\title{
A Comparative Study between Single Dose of Ceftriaxone, Metronidazole and Gentamicine as a Prophylaxis versus Conventional Dose Antibiotic in Hysterectomy in BSMMU
}

\author{
SA MUNMUN ${ }^{\mathrm{a}}$, R ARA ${ }^{\mathrm{b}}$, S CHOWDHURY', MMA SARKAR ${ }^{\mathrm{d}}$, SB CHOWDHURY ${ }^{\mathrm{e}}$, \\ N PARVIN $^{\mathrm{f}}$, R SULTANAg, S ISLAM ${ }^{\mathrm{h}}$
}

\begin{abstract}
Summary:
A prospective study was done in the Department of Obstetrics \& Gynaecology, BSMMU, Dhaka from January 2006 to December 2006. Hundred cases were studied during this period. The patients admitted for hysterectomy operation were divided into group $A$ and group B. In group A 50 patients received prophylactic injectable $1 \mathrm{gm}$ ceftriaxone, $500 \mathrm{mg}$ metronidazole and $80 \mathrm{mg}$ gentamicine one hour before operation. In group B 50 patients received conventional antibiotic comprising ciprofloxacin for 7 days (both I.V and Oral), metronidazole for 5 days (both I.V and oral) and gentamicine for 3 days (I.V/I.M). After fulfilling the inclusion and exclusion criteria the patients were randomly assigned to receive either parenteral loading dose of $1 \mathrm{gm}$ Ceftriaxone, $500 \mathrm{mg}$ Metronidazole and $80 \mathrm{mg}$ Gentamicine (Group-A) pre-operatively or conventional dose of antibiotic (GroupB). Relevant careful clinical records and data were kept on predesigned proforma. Incidence of post-operative complications, operative time and hospital stay were recorded for each patient. Data was analyzed using SPSS program with the consultation of the statistician. Because of nature of the analysis, only chi-squire(X2) test was applied. Most of
\end{abstract}

Introduction:

The prevention of infection in surgical patient undergoing operation is a major challenge. The use of antibiotic

a. Dr. Salma Akter Munmun, Medical Officer, Department of Obs \& Gynae, Bangabandhu Sheikh Mujib Medical University.

b. Dr. Rowson Ara, Medical Officer, Department of Obs \& Gynae, Bangabandhu Sheikh Mujib Medical University.

c. Dr. Shiuly Chowdhury, Assistant Professor, Department of Obs \& Gynae, Bangabandhu Sheikh Mujib Medical University.

d. Dr. Mst. Manjumun Ara Sarkar, Register, Department of Gynae Oncology, NICRH, Mohakhali, Dhaka

e. Prof. Saleha Begum Chowdhury, Department of Obs \& Gynae, Bangabandhu Sheikh Mujib Medical University.

f. Dr. Nahida Parvin, Medical Officer, Department of Obs and Gynae, Bangabandhu Sheikh Mujib Medical University.

g. Dr. Rabeya Sultana, Assistant Professor, Department of Obs \& Gynae, City Medical College, Gazipur

h. Dr. Sabiha Islam, Medical Officer, Department of Obs and Gynae, Bangabandhu Sheikh Mujib Medical University

Address of Correspondence: Dr. Salma Akter Munmun, Mailing address: Room no. 827, Block-C, Department of Obs \& Gynae, Bangabandhu Sheikh Mujib Medical University, Phone: +8801715000137, E-mail: salma.a.munmun@gmail.com

Received: 31 May, 2013

Accepted: 8 May, 2014 the patients (64\% in Group-A and $67 \%$ in Group-B) were from low socio-economic class. Significant number of patients were anaemic (Hb\% between 50-55\%) and duration of operation was within 60-89 minutes in most of the cases. There were $3(6 \%)$ post operative wound infection in GroupA and 2(4\%) post operative wound infection in Group-B after abdominal hysterectomy. 1 patient of Group-A and 1 patient of Group-B developed wound infection after vaginal hysterectomy operation. So, there was no significant difference in post-operative wound infection between Group$A$ and Group-B. Length of post-operative hospital stays in both groups were within 5-9 days (Group-A 90\% and GroupB 92\%). The study demonstrates that there is no significant difference regarding surgical outcome between Group-A and Group-B. Moreover the patient of Group-A needs antibiotic cost only Tk. 220 and Group-B needs of about Tk. 640, so that it saves about $T k .420$ which supports the economic benefits for Group-A and cost effectiveness.

Key Words: Hysterectomy, Antibiotics, Parenteral, Prohpylaxis, Conventional

(J Banagladesh Coll Phys Surg 2014; 32: 149-152)

prophylaxis has been shown to prevent post surgical wound infection. When employed rationally, significant reduction in the mortality and morbidity and saving in resources can be achieved ${ }^{1}$. Most of the patients who undergo major operation in public hospital are of low socio-economic group with poor nutritional status and the chance of cross infection in hospital is more. Better outcome after major surgical procedure mainly depends upon the nutritional status of the patient, type of surgical wounds maintenance of strict asepsis during operation, post operative care etc. In hospital there is more chance of cross infection due to overcrowding. So usually we treat the patient with conventional parenteral antibiotic therapy followed by oral Ciprofloxacin for 7 days, Metronidazole for 5 days and parenteral Gentamicine for 3 days to prevent infection.

But to reduce the expenditure of patient and minimize the side effects of conventional long time antibiotic therapy, single dose preoperative antibiotic as a prophylaxis can be tried alternatively to control the infection. 
It has been learnt from the different study that proper aseptic technique alone could reduce but not completely eliminate the bacterial contamination of the surgical field ${ }^{2}$. Therefore, the need for antibiotics as supplement to aseptic technique became more widely accepted specially in a situation like our overcrowded hospital.

Different study showed that broad spectrum antibiotics and administration of more than one dose were more efficacious ${ }^{3}$.

The effective use of prophylactic antibiotic depends upon the appropriate timing of their administration. Parenteral antibiotic in sufficient doses generally should be given within 1 hour before the operation which help to achieve the therapeutic drug level both in the blood and related tissue during the operation ${ }^{4}$. The antibiotics used must have better tissue penetration, prolong half life and should cover most of the polymicrobes involves in per and post operative infection. Ceftriaxone, Metronidazole and Gentamicine when administered together as a prophylaxis can fulfill the above criteria of a good antibiotic.

\section{Materials and Methods:}

Prospective type of comparative study was done in the Department of Obstetrics and Gynaecology, Bangabandhu Sheikh Mujib Medical University (BSMMU), Dhaka from January 2006 to December 2006. All patients who were admitted for hysterectomy were included. Patient with impaired renal function, patient with hypersensitivity to penicillin group of drugs and patient with previous history of infection or any focus of infection in the body preoperatively were excluded from the study. After taking history, clinical examination was done by the investigator. Pre-operative anaesthetic check up was done for surgical fitness. When the patient was found to be fit for operation, one hour prior to surgery single dose of parenteral triple antibiotic was given to one study group (Group-A) and conventional dose antibiotic to another study group (Group-B). Patients were randomly assigned to receive parenteral one dose of 1 gm Ceftriaxone, 500 gm Metronidazole and $80 \mathrm{mg}$ Gentamicine (Group-A) or conventional dose of Ciprofloxacine for 7 days, Metronidazole for 5 days and Gentamicine for 3 days (Group-B). From both the group required information where recorded in the preformed check list. Prospective analysis was done by Frequency Test to get the percentage. Statistical analysis was done by chi-square test for measuring the association in order to answer the research questions. All the data were entered into the template of SPSS software after necessary screening and both qualitative and quantitative analysis were performed accordingly.

\section{Results:}

This comparative study was conducted to determine whether only single dose of Ceftriaxone, Metronidazole \& Gentamicine prophylaxis in hysterectomy operation is effective in controlling post operative wound infection.

Wound infection was observed in four patients (8.5\%) of Group-A \& three patients (6.25\%) of Group-B. There was no significant difference $(p>0.05)$ in terms of wound infections in both abdominal hysterectomy and vaginal hysterectomy.

The study findings show that only single dose of $1 \mathrm{gm}$ Ceftriaxone, $500 \mathrm{mg}$ Metronidazole and $80 \mathrm{mg}$ Gentamicine is as effective as conventional dose. Moreover prophylactic dose group patient is benefited due to their easy drug administration, fewer prick, fewer side effect and cost effectiveness.

Study showed that to decrease post operative wound infection needs appropriate aseptic surgical technique and improvement of patients nutritional status and anaemic condition.

Figure 1: Bar diagram showing number of patients in different hysterectomy group (Total 100 patients were taken into trail).

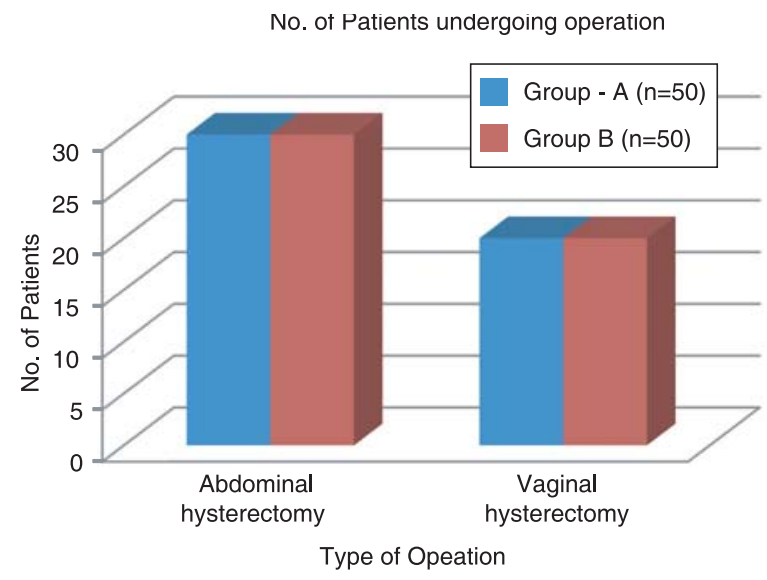

Fig.-1:

Table-I

Age distribution of both groups $(n=95)$

\begin{tabular}{lcc} 
Age Group & Group-A $(\mathrm{n}=47)$ & Group-B $(\mathrm{n}=48)$ \\
\hline $25-34$ & $13(28 \%)$ & $12(25 \%)$ \\
$35-44$ & $20(43 \%)$ & $21(44 \%)$ \\
$45-54$ & $10(21 \%)$ & $9(19 \%)$ \\
$55-64$ & $4(8 \%)$ & $6(12 \%)$ \\
\hline
\end{tabular}

$\mathrm{X}^{2}=0.5066, \mathrm{p}>0.50$ (Not significant) 
It is seen that about $50 \%$ of the patients are in $35-44$ years age group. There is no difference in age between the two groups of patients.

\section{Table-II}

\begin{tabular}{lcc}
\multicolumn{3}{c}{ Socio-economic condition } \\
& Group-A (n=47) & Group-B (n=48) \\
\hline Low & $30(64 \%)$ & $32(67 \%)$ \\
Middle & $14(30 \%)$ & $13(27 \%)$ \\
High & $3(6 \%)$ & $3(6 \%)$ \\
\hline
\end{tabular}

$\mathrm{X}^{2}=0.0919, \mathrm{df}=2, \mathrm{p}>0.50$ (Not significant)

Low $=<$ Tk. $10,000 /-$ to $15,000 /-$ per month

Middle $=>$ Tk. $15,000 /-$ to Tk. 30,000/- per month

High $=>$ Tk. 30, 000/- per month

Most of the patients are of the low income group. Only $6 \%$ is of high income group.

\section{Table-III}

Analysis of risk factors for infection in study group.

Observed association of different variables among 7 (seven) patients of both group who experienced infection.

\begin{tabular}{lccccc}
$\begin{array}{l}\text { No. of } \\
\text { patients }\end{array}$ & Age & $\begin{array}{c}\text { Weight } \\
\text { (Ibs) }\end{array}$ & $\begin{array}{c}\text { Socio-economic } \\
\text { condition }\end{array}$ & Hemoglobin & $\begin{array}{c}\text { Duration } \\
\text { of operation } \\
\text { in min }\end{array}$ \\
\hline 1 & 52 & 180 & Low & 50 & 120 \\
2 & 45 & 120 & Low & 50 & 80 \\
3 & 43 & 130 & Low & 60 & 80 \\
4 & 52 & 130 & Low & 52 & 90 \\
5 & 57 & 72 & Low & 55 & 90 \\
6 & 54 & 110 & Low & 50 & 90 \\
7 & 49 & 120 & Low & 60 & 90 \\
\hline
\end{tabular}

All patients were of low socio-economic status. $\mathrm{Hb} \%$ was within 50-55\%, weight was between 72-180 lbs, duration of operation was 80-120 minutes.

\section{Discussion:}

The present study was designed to compare the efficacy of only single dose of Ceftriaxone, Metronidazole and Gentamicine versus conventional multi-dose regimen in hysterectomy operation to prevent post operative wound infection which revealed no significant difference between the groups. Hysterectomy is one of the most frequently performed major operation in gynaecology 5 . Many randomized trial were performed worldwide to find out the effectiveness of antibiotic prophylaxis in high risk patient ${ }^{6}$. Appropriate choice of prophylactic antibiotics require an understanding of the polymicrobial nature of the endogenous microflora each site ${ }^{4}$. There was no trial of antibiotic prophylaxis in low risk group worldwide i.e the patient with aseptic surgery. They recommended the use of prophylactic antibiotic in high risk patients who have prosthetic implant, colorectal surgery etc. and also in those in whom the development of an infection might be associated with a catastrophic end result ${ }^{7}$. A study done by Naz (2001) showed single dose offers patients compliance. Patients of control group complaint of many side effects, like nausea, vomiting, dizziness, constipation etc. with conventional treatment which did not occur with that of the single dose prophylactic antibiotic. Most of the complaints were due to the use of metronidazol. Single dose prophylaxis also decrease the workload of the hospital staff ${ }^{8}$.

In this study at the time of randomization, the general characteristic of the patient in both groups showed no significant difference (table I \& II). So it is concluded that this comparative study was carried out in matched groups of patients so that it didn't influence the outcome.

The prophylactic use of antimicrobial agents to reduce post operative wound infection has been frequently advocated. The objective of pre-operative prophylaxis is to prevent post-operative infections which are the primary cause of morbidity and mortality in patient undergoing surgery today ${ }^{9}$. Investigators demonstrated that proper aseptic technique alone could decrease but not completely eliminate bacterial contamination of the surgical field. Therefore the need for antibiotics to supplement aseptic technique becomes more widely accepted $^{10}$.

Risk of infection may also depends on age, general condition, duration of operation, amount of blood loss during surgery and number of blood transfusion required ${ }^{9}$.

Hoplin L (2000) showed that multiple dose regimen for prophylaxis appears to offer no added benefit over single dose regimen ${ }^{11}$. This present study findings matched with the findings of Hoplin.

Some studies also showed administration of intermittent intramuscular injection produces lower blood levels and retarded entry of antibiotics into the wound fluid ${ }^{12,13}$.

In the present study single parenteral dose of $1 \mathrm{gm}$ Ceftriaxone, $500 \mathrm{mg}$ Metronidazole and $80 \mathrm{mg}$ Gentamicine Intravenous were given stat in Group-A. There were $3(6 \%)$ post operative wound infection in Group-A and 2(4\%) in Group-B. 1 patient of Group-A and 1 patient of Group-B developed wound infection after vaginal hysterectomy operation. So, there was no significant difference in post operative wound infection between Group-A and Group-B in respect of vaginal 
hysterectomy. In the both study group, significant number of patients were anaemic ( $\mathrm{Hb} \%$ between 50 $55 \%$ ) and duration of operation was within 60-89 minutes in most of the cases (in Group-A 51\% and in Group-B 58\%). Most of the patients (64\% in Group-A and $67 \%$ in Group-B) were from low socio-economic class, it is the most striking feature that indicates poor nutritional status of the patient. So, it is seen that patients general condition i.e. $\mathrm{Hb} \%$ and nutritional status have marked influence on post operative wound infection, which is supported by other studies ${ }^{4}$.

Begum A. (1981) has shown in her study that post operative wound infection is more common in those patients who need prolong time for operation. In this study there was no significant difference of operation time found between two groups. So it has no influence on the result of the present study ${ }^{14}$.

In both group of study there was no significant difference regarding intra operative adhesion and type of suture materials used in skin closure.

The study demonstrate that there is no significant difference in post operative wound infection, or post operative hospital stay between Group-A \& Group-B.

This study clearly demonstrated that there is no significant difference in abdominal wound infection in both groups ( $\mathrm{p}>0.05)$. Considering vaginal hysterectomy there is also no significant difference ( $p>0.05)$. So, it is shown that only loading dose is as effective as conventional multi regimen.

Moreover the patient with Group-A needs antibiotic cost only 220 tk. and Group-B needs of about 640 tk. that saves about 420 tk. which support the economic benefits for Group-A.

Single dose offers patients compliance. Side effects like nausea, vomiting, dry mouth, metallic taste etc is more in Group B patients. This study result suggests that these side effects were less in Group A patients.

There is no significant difference in morbidity between prophylactic antibiotic \& routine conventional antibiotic in hysterectomy operation. To reduce post operative wound infection as a whole it needs aseptic surgical technique and improvement of patients general condition. Single dose prophylaxis is effective for most procedures and results in decreased toxicity and antimicrobial resistance ${ }^{15}$.

\section{Conclusion:}

Single dose antibiotic prophylaxis offers patients compliance, cost effectiveness and minimum side effect but conventional antibiotic offers less patient compliance with expensive treatment cost and probability of more side effects. Postoperative wound infection not only depends upon antibiotic use but also on many other factors like age, nutritional status, hygienic condition, anaemic status and duration of operation, blood loss during operation and amount of blood transfusion.

The findings of this study demonstrated that administration of prophylactic antibiotic rather than conventional antibiotic at hysterectomy operation is not associated with significant difference in post-operative morbidities.

\section{References:}

1. A Swapokee N, Vithayapichet S, Heller RF. Pattern of antibiotic use in medical ward of a University Hospital, Bangkok, Thailand, Rev Infect Dis 1990;12:136-141.

2. Utualp K. Condon RE. Antibiotic prophylaxis for scheduled operative procedures. Infect Dis Clin North Am. 1992, 6: 613625.

3. Sutton C. Hysterectomy: a historical perspective: Baillierseclinobsobster-Gynaeco/1997: (1); 1-22.

4. Nichols RL MD. Use of prophylactic antibiotics in surgical practice. Am J Med. 1981 March; 70(3):686-92.

5. Dicker RL, Scally MJ, Green span JR et al. Hysterectomy among women of reproductive age: trends in the United States. 1970-1978. JAMA. 1982; 248:323-27.

6. Waddell TK, Rotstein OD. Antimicrobial prophylaxis in surgery. Committee on antimicrobial agents, Canadian Infectious disease Society. CMAJ, 1994 Oct 1; 151(7): 925-31.

7. Anonymous Antimicrobial prophylaxis in surgery; Med Lett Drugs Ther 1987; 29.91.94.

8. Naz MZ. A comparative study between single dose cephradine as a prophylaxis versus conventional dose antibiotic in major gynaecological procedure in SSMC \& MH. Dissertation for FCPS, BCPS, Mohakhali, Dhaka, 2001.

9. Gudiol F. Surgical Antibiotic prophylaxis tradition and change. Int J Clin Pract Suppl. 1998 June; 95:37-43.

10. Esposito S. Is single dose antibiotic prophylaxis sufficient for any surgical procedure? J Chemother. 1999 Dec; 11(6):556-64.

11. Condon RE. Preoperative preparation of the colon. Surg Gynecol Obstel. 1971;132:323-337.

12. Nichols RL. Intra Abdominal sepsis; Characterization and treatment. J Infec Dis. 1977 Mar; 135 suppl:54-57.

13. Nichol RL, Condon RE. Role of the endogeneous gastrointestinal microflora in postoperative wound sepsis. Surg Annu. 1975;7: 279-93.

14. Begum A. A study of metronidazole prophylaxis in obstetrical and gynaecological surgery. Dissertation for FCPS, BCPS, Mohakhali, Dhaka, 1981, P-119.

15. Lampiris HW MD \& Maddix DS, Pharm D. Clinical use of antimicrobial agent. In: Katzung Bertram G. Basic \& Clinical pharmacology. $9^{\text {th }}$ edition. Boston, McGraw Hill; 2004.p-849. 